\title{
Chemistry in a sustainable society
}

\author{
Elena Bernardi • Fabrizio Passarini • Luciano Morselli
}

Received: 12 June 2014 / Accepted: 17 June 2014 / Published online: 10 July 2014

(C) Springer-Verlag Berlin Heidelberg 2014

"Chemistry in a Sustainable Society" is the title chosen for the 14th Italian Congress of the Environmental and Cultural Heritage Chemistry Division held in Rimini in June 2013 (Bernardi et al. 2014).

Since the 1970s, several definitions have been given in order to explain what sustainability is. The most well known and frequently cited is the one stated in 1987 by the Brundtland Commission: "Sustainable development is development that meets the needs of the present generation without compromising the ability of future generations to meet their own needs." (WCED 1987). According to the US Environmental Protection Agency, "Everything that we need for our survival and well-being depends, either directly or indirectly, on our natural environment. Sustainability creates and maintains the conditions under which humans and nature can exist in productive harmony, that permit fulfilling the social, economic and other requirements of present and future generations" (EPA 2014).

In order to indicate whether the world is becoming more sustainable, in 2006, the Sustainable Society Foundation started to calculate the Sustainable Society Index (SSI), based on three dimensions: environmental well-being, human well-being and economic well-being. The last evaluation available (van de Kerk et al. 2012)

Responsible editor: Philippe Garrigues

E. Bernardi $\cdot$ F. Passarini $(\triangle) \cdot$ L. Morselli

Department of Industrial Chemistry "Toso Montanari”,

Alma Mater Studiorum - University of Bologna,

Viale del Risorgimento 4, 40136 Bologna, Italy

e-mail: fabrizio.passarini@unibo.it

F. Passarini $\cdot$ L. Morselli

Interdepartmental Centre for Industrial Research "Energy \&

Environment", Alma Mater Studiorum - University of Bologna,

Via Angherà 22, 47921 Rimini, Italy indicates that the overall global sustainability score is improving, but environmental well-being is declining mainly due to financial crisis, fast growing countries and climate skepticism. Therefore, actions are needed because environmental sustainability is one of the pillars of a sustainable society. Thinking about both environmental and human well-being, some questions come immediately to mind: protection of natural resources, impact of human activities on air, water and soil quality, and impact of environmental conditions on human health. Nevertheless, a further aspect cannot be neglected: culture and cultural heritage conservation, as no society can be said sustainable if source and symbols of its identity get lost.

In facing these issues, Environmental and Cultural Heritage Chemistry can play a crucial role, helping in understanding environmental and decay processes, identifying causes and finding possible solutions.

Papers included in this special issue are a selection from the scientific works presented at the "Chemistry in a Sustainable Society" Congress and cover several topics related to chemistry and sustainability, ranging from pollutants characterization and identification of emission sources to the fate of pollutant in environmental matrixes with possible health effects, techniques to assess environmental contamination, waste management, decay, cleaning and conservation of cultural heritage.

In particular, the first group of papers deals with atmospheric pollution due to particulate matter.

Gatto et al. present a study performed within the LIFE+ European Project "EXPAH" and aimed at monitoring the personal exposure of elementary school children and elders to polycyclic aromatic hydrocarbons contained in fine particulate matter in the city of Rome. Riccio et al. extend traditional source apportionment techniques using a joint Eulerian/ Lagrangian approach; this approach applied to the urban area 
of Naples (Southern Italy) suggests that PM concentration is strongly influenced not only by local sources but also by transboundary emissions. Iovino et al. move the focus from the mainly studied metropolitan areas to the outskirts, investigating the contribution of different sources to $\mathrm{PM}_{10}$ concentration in a Southern Italy suburban area. Biomass burning has recently become a subject of public concern as a source of, among others, fine and ultrafine particles. Dambruoso et al. analyse the impact of burning pruning waste from olive trees, a common usage in Southern Italy, on the physical and chemical characteristics of particulate matter.

With regard to indoor air quality, VOC concentrations in a multi-storey shopping mall were analysed by Amodio et al., highlighting the importance of carrying out both high spatial resolution and high temporal resolution monitoring when environments with a complex emission scenario are considered.

Another paper deals with dioxins and PCB, whose human exposure is mainly due to contaminated food; in order to protect both marine ecosystem and human health, PCDD/Fs and dioxin-like PCBs in mussels from Ionian Sea around Taranto (Southern Italy) were determined by Di Leo et al..

As regards soils and sediments, Bilo et al. compared total reflection X-ray fluorescence spectroscopy (TXRF) with different spectroscopic techniques and propose TXRF as a suitable technique for the assessment of metal contamination in this kind of environmental matrixes. Soil, as well as water, can be affected by emerging contaminants like drugs that can reach environmental waters still in the pharmaceutically active form: this is the case of fluoroquinolones. In order to study the environmental fate of this antibiotics family, Sturini et al. examined their photodegradation at the water-soil interface and in soil under natural solar light.

Another group of paper concerns waste management. Among these, Mercurio et al. report a procedure to assess the melting behavior of SRF-derived ashes, by means of a heating microscope, in order to optimize energy recovery from waste. The issue of managing hazardous substances contained in waste electrical and electronic equipment (WEEE) is considered by Barbieri et al.. Their study presents a rapid screening of different chemical and mechanochemical processes to reduce lead content in waste cathode ray tube glass. Lancellotti et al. investigate the possibility of using zeolite substrate containing phosphatic waste for the release agronomical nutrient, such as phosphorus, into soils.

The last group of papers concerns cultural heritage characterization, cleaning and conservation. Innovative treatments based on nanoparticles are also presented. In fact, in recent years, also in the cultural heritage field, as well as in many others, nanoparticles properties are deeply investigated to improve cleaning, restoration and conservation treatments. In particular, Arizio et al. investigate the degradation mechanism affecting the amalgam layer of ancient mirrors, while
Casoli et al. analyse how different kinds of aqueous gel can interact with lipidic paint binders, thus providing suggestions on the proper application of aqueous methods with gelling agents for cleaning painted surfaces. Photocatalyst titanium dioxide is widely studied to realize material surfaces joining together self-cleaning and antipollution properties. In order to exploit these characteristics also for protecting historic stones, Bergamonti et al. developed and tested a promising selfcleaning photocatalytic coating based on water nanosols of $\mathrm{TiO}_{2}$ nanoparticles. Considering that the integrity and aesthetical appearance of historic stone are threatened not only by chemical-physical agents, but also by microbial colonization, Bellissima et al. successfully investigated the ability of silver nanoparticles to inhibit bacterial viability on stone surfaces.

The guest editors would like to thank all the authors that contributed with their papers the realization of this special issue, and also to the ESPR Editor-in-Chief Philippe Garrigues and Editorial Assistant Emmanuelle PignardPéguet for their kind support.

\section{References}

Bernardi E, Passarini F, Morselli L (2014) Fourteenth National Congress of the Environmental and Cultural Heritage Chemistry Division, "Chemistry in a Sustainable Society," held in Rimini (Italy) in June 2013. Environ Sci Pollut Res. doi:10.1007/s11356-014-2656-7

EPA, What is sustainability?, http://www.epa.gov/sustainability/ basicinfo.htm\#sustainability, accessed 13/2/2014

van de Kerk G., Manuel A., SSI-2012, Sustainable society index (2012) Sustainable Society Foundation, available at http://www. ssfindex.com/

WCED (1987) Our common future, chair: Gro Harlem Brundtland. World Commission on Environment and Development, Oxford University Press

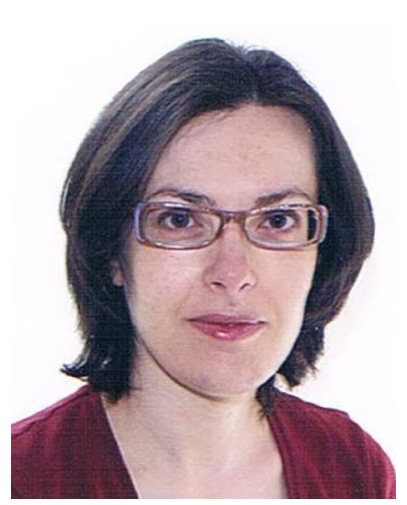

Elena Bernardi is an Assistant Professor in Environmental Chemistry and Cultural Heritage at the Department of Industrial Chemistry "Toso Montanari" University of Bologna. She received her Ph.D. in Industrial Chemistry in 2005 from the University of Bologna. Since 2012, she is a member of the Editorial Board of the international journal, Environmental Science and Pollution Research.

The research activity is mainly focused on the study of atmospheric pollutants/depositions and their interactions with different environmental receptors, materials constituting cultural heritage and protective products. From 2011 to 2013, she was involved in the National Project "Innovative Methods for the Conservation of Gilded Bronzes", funded by the Italian Ministry of Education and Research. 


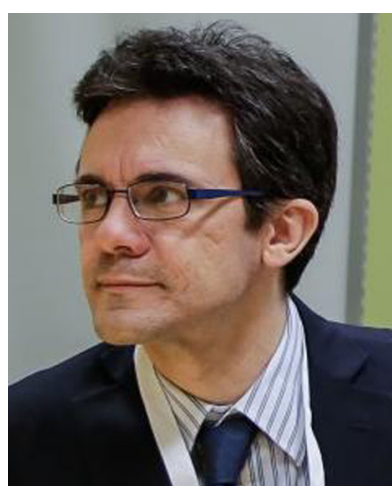

Fabrizio Passarini is an Assistant Professor in Environmental Chemistry and Cultural Heritage at the Department of Industrial Chemistry "Toso Montanari" University of Bologna. He received his Ph.D. in Chemistry in 2000 from the University of Venice. He has been the project coordinator of an "Erasmus Intensive Programme" financed by EU in the framework of the "Lifelong Learning Programme". He is President in charge of the Environmental and Cultural Heritage Chemistry Division of Italian Chemical Society, elected on 17 December 2012. He is the vice-director of the Interdepartmental Center for Industrial Research "Energy and Environment", University of Bologna.

The scientific research deals with topics concerning the impact on the environment due to sources of anthropic origin. In particular, he deals with: waste management and sustainability parameters of industrial processes and products (LCA, MFA); environmental monitoring to assess the impact produced by industrial processes; study of the influence of atmospheric contamination on cultural heritage decay.

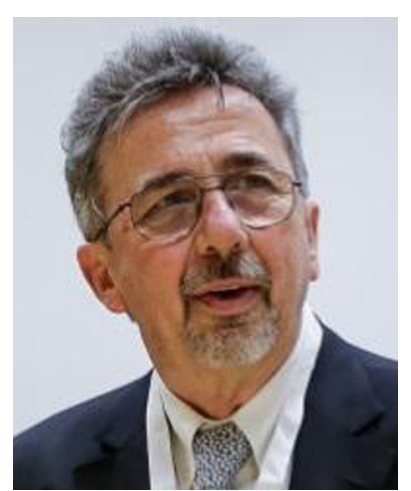

Luciano Morselli is a Full Professor in Environmental Chemistry and Cultural Heritage at the Department of Industrial Chemistry "Toso Montanari" - University of Bologna. He has been President of the Course for the Degree in Chemical Technologies for the Environment and for Waste Management. His research activity covers many fields: atmospheric deposition chemistry, trace pollutants in environmental samples, micro-pollutants effluents from municipal solid waste incinerators, LCA applied to integrated waste management systems, integrated waste management technology and environmental control and interaction of pollutants with cultural heritage. He was author and co-author of more than 80 publications in international scientific journals and books, editor of about 30 monographs and 20 technical reports. Member of several scientific societies, he was President of the Italian Division of Environmental and Cultural Heritage Chemistry. Among other appointments, he was scientifically responsible for laboratory networks and of more than 30 researches commissioned by public institutions and private companies in the last 10 years. 